\title{
The Inspiration of CDIO Engineering Education Mode to University Physics Experiment Teaching
}

\author{
Juan Fan \\ Experimental Center of Northwest University for \\ Nationalities, \\ Lanzhou, China \\ E-mail: fanjuan@126.com
}

\author{
Guoheng Zhang \\ Electrical Engineering College of Northwest University for \\ Nationalities, \\ Lanzhou, china \\ Corresponding author e-mail: zhgh0325@163.com
}

\begin{abstract}
CDIO engineering education mode is the latest achievement of international engineering education reform in recent years. This paper quote the CDIO engineering education idea to the university physics experiment teaching, as the experimental project for guider, emphasize learning by doing, assign different tasks to students in the form of group cooperation, take the product research and development to run the system's four life cycle: conceive, design, implement and operate as the experimental process. Students conceive experiment plan firstly; then design and put forward the experimental method; lastly students start to carry out the plan and analyze data or processing. The process let students learn how to learn by practice, improve the enthusiasm of learning. The process pays more attention to the student's ability development. The results indicate that the cultivated students have the ability of solving practical problems, communication, teamwork and innovating knowledge.
\end{abstract}

Keywords-CDIO theory; CDIO engineering education mode; statistic figure; physical experiment teaching; the new relationship between teachers and students

\section{INTRODUCTION}

With the advancement and development of science and technology, the society's need for talents capacity is more and more strict. The talents in the new century must have high quality, good educated and high-level. The talents must have a solid basic knowledge of professional and outstanding creative thinking ability. Their comprehensive quality and practical ability are strongly. The main purpose of CDIO engineering education mode is to cultivate students to become a qualified engineers, so that students can understand how to conceive, design, implement and operate complex and high-value-added products, processes and systems. The process makes students to become mature and responsible. The students should be familiar with professional and technical knowledge, with personal and interpersonal skills, and are able to interact well with the masses, with the ability of teamwork and leadership new products [1]. This concept is consistent with the current training objectives of innovative talents. College physics course is the foundation of science and engineering students learn professional knowledge. The CDIO engineering education mode is used to college physics experiment teaching, emphasized learning by doing. This mode is helpful to cultivate students' practice ability and conducive to innovation.

\section{THE CDIO THEORY}

CDIO means conceive, design, implement and operation. CDIO engineering education mode is an advanced engineering education concept, which was put forward and created by Swedish Royal Institute of Technology, Chalmers University of Technology, Linkoping University and a team headed by the United States Academy of Engineering Professor Ed. Crawley of Massachusetts Institute of Technology. Since 2000, the four universities have constituted cross-country studies combination. The combination obtained the Knut and Alice Wallenberg Foundation heavily subsidized nearly \$ 16 million After four years of exploration and research, they created the advanced engineering educational philosophy [1].

CDIO engineering education mode is the latest achievements of international engineering education reform in recent years. CDIO is the concentrate generalization and abstract expression of "the principle of learning by doing" and "education and learning based on the project" [2]. CDIO mode is on the basis of the engineering project's life cycle as the supporter, including products, production processes and systems from research and development to operate. The process makes student to study engineering voluntary, practice, organic connection between courses [3]. CDIO engineering education inherited and developed the concept of Europe and the United States more than 20 years of engineering education, put forward the scheme for ability training, comprehensive guidance, implementation process and 12 standards [1] Comprehensive guidance includes cultivation program, teaching method, teachers, students and the learning environment. Twelve standards are used to inspection study result, which is operable. In $12 \mathrm{CDIO}$ standards, there are seven critical and fundamental, which reflects the CDIO methodology characteristics, it is different from other educational reform programs; five standards are to be supplement, which greatly strengthened the CDIO methodology and reflect the effective practice of engineering education [4].

\section{THE LITERATURE STATISTICS OF THE CDIO THEORY}

According CNKI database statistics, over the past ten years, literature references about CDIO theory increased linearly. For example, we input the keyword "CDIO theory" to retrieval,

Project supported by the Fundamental Research Funds for the Central Universities. 
ten years data are shown in Figure 1. In 2005, there was only 1 journal article, 3 theses. About 2008, 29 journal articles and 5 theses were collected in CNKI database. Until 2014, the database had already included 710 journal articles and 707 theses.

However, when we input the keyword "CDIO engineering education mode", after retrieval, we found the articles and theses number about ten years increased obviously, the result are shown in Figure 2. Compared with Figure 1, In 2005, about 125 journal articles and 40 theses were included by CNKI database, which refer to CDIO engineering education mode. In 2012, the number had already reached to 865 and 79. By 2013, the paper number about CDIO engineering education mode added up to 1026 , and the theses number was 82 .

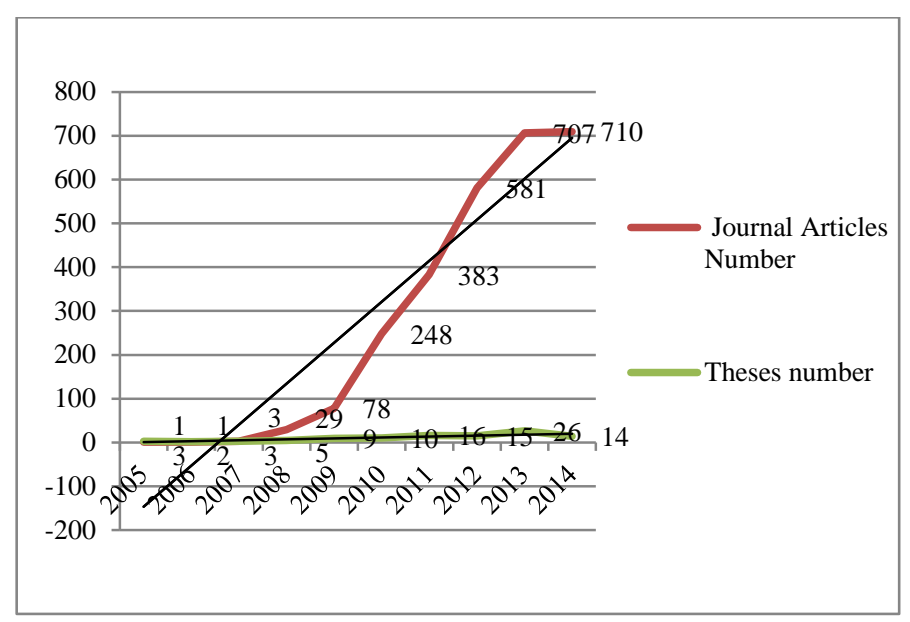

Fig.1.The statistical figure about CDIO theory (2005-2014)

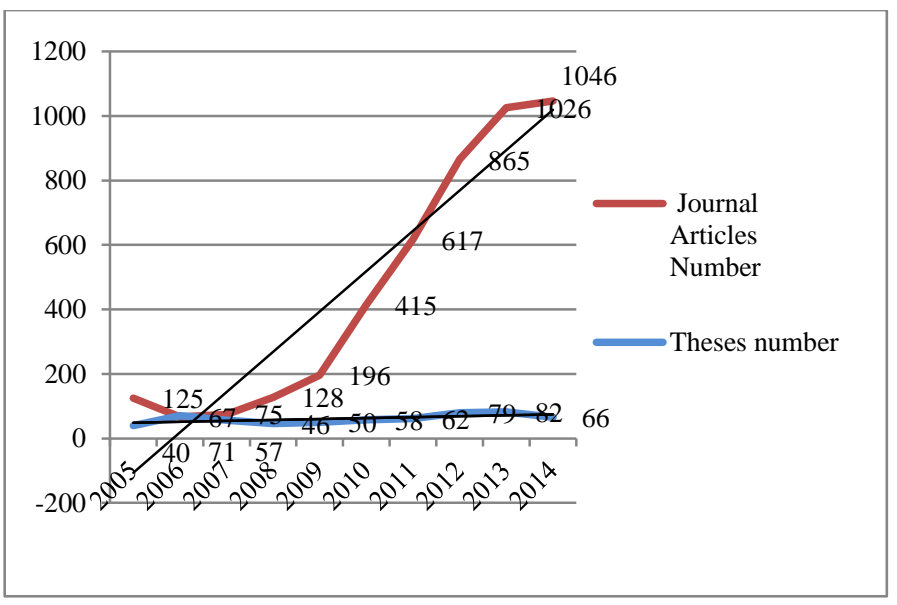

Fig.2. The statistical figure about CDIO engineering education mode (20052014)

According to Figure 1and Figure 2 shows, journal articles and theses on CDIO theory and CDIO engineering education mode are to recognize a linear growth trend, both of which the growth rate of journal articles is significantly higher than the number of thesis. The number of literatures about CDIO engineering education mode increased faster, and the increase range is significantly higher than the CDIO theory.
The reason is as follows:

1) The social requirement condition for talents is more and more high.

2) Engineering education to cultivate qualified engineers has obtained the attention of the education departments at all levels.

3) Colleges and universities as the cradle for the training, responsibility.

The paper titles in CNKI database indicate that most university researchers used CDIO engineering education mode for reform in their own professional construction, courses teaching or on the students' innovative education. They combined CDIO mode with their professional characteristic in order to reform or practice, developed a series of curriculum plan, which was suitable to their university professional development. All these achieved remarkable effect. Some examples are shown below.

As early as 2007, Christopher Teoh and Nhut Tan Ho adopted CDIO mode to reform experiment teaching [5-6]. In China, Engineering College of Shantou University have already implemented CDIO mode in five undergraduate majors [7]. Tsinghua University applied CDIO engineering teaching methods in two courses, such as "data structure" and "database principle" [8]. In 2010, Jiang Nan and Sun Zhigang reformed electromagnetism experiment by using CDIO mode [9]. In 2014, Shan xian in China University of petroleum applied the CDIO education concept to engineering students in the process of the Linear Algebra teaching [10]. In addition to this, liberal arts are also reference CDIO concept for teaching reform. For example, Chen Dongsong in Jilin institute of chemical industry cited CDIO concept in college English teaching, which improve the learning efficiency and comprehensive ability of students [11]. Guangzhou Bai Yun university's teacher Liu Juan combined multimodal teaching with CDIO mode, applied to college English teaching, to build a new teaching mode, which is "classroom teaching, network resources platform for teaching, and extracurricular autonomous learning", the new method cause the university English teaching keep up with the pace of the times development [12].

\section{THE CHARACTERISTICS OF THE TRADITIONAL UNIVERSITY PHYSICS EXPERIMENT TEACHING}

University physics experiment is an independent course. According to teaching syllabus, physics experimental courses generally are opened in the second semester of Grade 1 and the first semester of Grade 2 and go along with physics theory course. The experimental courses are not only cultivate students' practical skills, realize the combination of theory and practice, but also help students to consolidate the theoretical knowledge.

Traditionally, experimental teaching mode is a cramming teaching. Teachers often tell students experimental principles, experimental purposes, experimental procedures and equipment operating precautions in laboratory. The students take notes mechanically, watch the teachers' demonstrate, measure experimental data, record the result of the experiment, 
analyze data and processing. The traditional mode would cause students lack of positive thinking and active learning. It is also not conducive to students' subjective initiative. A student can only operate a specific experimental apparatus, when he (she) confronts equipment, he (she) would be nervous or constraint because of incompetence.

So the traditional mode has great limitations, it is unfavorable to cultivate innovative talents.

\section{THE SPECIFIC COMBINATION OF CDIO ENGINEERING EDUCATION MODE AND UNIVERSITY PHYSICS EXPERIMENT TEACHING}

CDIO engineering education mode basing on the project starts at the four steps of conception, design, implementation and operation, regards the project as a guide, the implementation of the project for the process, emphasize learning by doing. The purpose of the CDIO engineering education is to make our students to be a successful engineer, who must have the technical knowledge, social consciousness and creative tendency [13]. The CDIO mode focuses on students' comprehensive ability. Students have the ability of autonomous learning, solving actual problem, communication, and team cooperation.

In order to change the traditional way of teaching physics experiment, schools can fully simulate the production of management, or directly cooperate with enterprises, combining the CDIO education concept and the university physics experiment teaching. During the physics experiment teaching, we should firstly make experimental plan on the basis of the syllabus and then carry out the experiment according to the schedule. Basically, an experimental project needs a week to complete. Based on the CDIO mode, we only need to list all experiment projects, regard the project as a guide, emphasize learning by doing, assign specific tasks to students, simulate the life cycle of product research, development and operation. The experiment process is similar to product's production process. During the process, the teacher is no longer dominated, but the students should give full play to the initiative. The specific process is as follows:

\section{A. Conceive}

In this stage, the task of students is to collect and sort information automatically, which is related to the specific experimental project requirements. Students are no longer dependent on the teacher's teaching. The same group of students can share their information and resources with others, discuss and determine the most reasonable plan to guide the next step work. This process pays more attention to emphasis on theory knowledge and the communication between students.

\section{B. Design}

After conceiving, students start to design experiment plan. They will determine to select which one experimental instrument, use what method, how to operate, how to measure experiment data, how to effectively implement the experiment result, etc. All problem need to be considered by the students with completing design tasks. In this stage, the students can make a comprehensive study and be a thorough master of theoretical knowledge and practical skill.

\section{Implement}

The implementation phase of physics experiment is to perform the process of design plan. These tasks need another part of students to execute. According to the design plan, students start to do specific project. During the implement process, the operate step is in accordance with the conception and design plan strictly. There are some inevitably new problems emergences. In order to solve the new problems, students may be look up information from library or computer network, discuss new problem and co-operate again. In this stage, the students' enthusiasm shows incisively and vividly. They come up questions boldly, discuss solving a problem and propose solutions. After training, most of students are no longer alone, withdrawn and conservative, instead they are an outgoing man. They are willing to share their knowledge and achievement, and their creative thinking is prominent.

\section{Operate}

In this stage, the task of students is what to combine with the above three stages, record the experimental data, analyze and processing. It is necessary to compare and discuss the experiment value with the theoretical, and analyze effect and deficiency from experiment result. We can also redesign plan if the experiment result is not ideal.

The four stages of operation process are similar to the whole process of the product from design to realize. The specific combination of CDIO and physics experiment teaching offers a chance for students to experience the working process of the enterprise production products and to shorten students' internship. The mode is well received by the society and enterprises. During the teaching, the students study theory knowledge autonomously and consciously, designs the experimental process, have the courage to ask questions, thinking and communication. The process is different from the traditional teaching mode, students not only learn the theoretical knowledge, but also learn how to learn. When they confront with new problems, they are no longer escape, instead they may check information and explore knowledge. Most of students have the ability to learn and explore knowledge, deal with problems. They are glad to share knowledge, communicate and cooperate with classmates. The whole combination process focuses on teamwork consciousness. In addition, the process of learning by doing is helpful to discover new knowledge and new experimental methods, and also to cultivate the ability of innovation practice.

\section{THE NEW RELATIONSHIP BETWEEN TEACHERS AND STUDENTS BASED ON THE CDIO MODE}

It is innovative to apply the CDIO engineering education mode in the process of college physics experiment teaching. But to someone who engaged in teaching work for a long time, it has challenge. The ninth standard of CDIO emphasizes to strengthen teachers' ability of CDIO. This standard requires teachers to take measures to strengthen their engineering ability, teamwork ability and building products ability. It's the best 
way to develop these in a professional field [14]. In order to improve the teachers' ability of CDIO, teachers can study or work in industry use their holiday or spare time, collaborate with experienced engineers in research project, or invite the experienced engineers to guide or help students.

The improvement of teachers engineering ability and standard are the key to implementing CDIO successfully. When using CDIO mode in college physics experiment teaching, teachers are no longer teach students step-by-step from textbook, but to create physical problem situations related our real life, inspire students to actively construct knowledge. The teachers are also to guide students to independent learning and learning consciously. Teachers themselves are not only master basic theory knowledge; operate equipment skilled, and also knowledgeable. They need to master the academic front and update knowledge at any time. They also need the ability to organize management and leadership students and the ability of strongly language expression. In addition, teachers must integrity, honest credible and become the idol in students mind. Therefore, teachers should take the initiative to accumulate their engineering experience, improve their ability of engineering continuously. The teachers are also providing appropriate engineering examples for students. More important, teachers will be a model of excellent engineers in students mind.

So, the new relationship between teachers and students from the teacher one-sided knowledge to interactive learning based on solving problems; at the same time, the learning process changes from inherited knowledge to construct knowledge actively. The teacher is a good example in engineering education process.

\section{CONCLUSION}

The CDIO mode is a kind of new education mode. We apply the ideas of conception, design, implement, and operation to college physics experiment teaching, which make the students to master the basic knowledge, learn how to autonomous learning, consolidate and improve theory knowledge. It's helpful to complementation of the theory knowledge and practical teaching each other. In the whole process of project implementation, everyone has his own task and keeps communicate with classmates. The cultivate form stimulate students' learning interest and improve teaching efficiency. In addition, it can help students to understand the working process of the industry and prepare for a good job. Finally, by the way of cooperative learning and solving problems, students can learn how to behave. They will be an honesty, integrity and responsible man. So, the CDIO engineering education mode has a profound impact on the cultivation of talents and is favored by the community

\section{ACKNOWLEDGMENT}

The authors would like to thank the fund supports of the Fundamental Research Funds for the Central Universities (31920150023).

\section{REFERENCES}

[1] P. Gu, M. Shen, and X. Lu Translation, Rethinking Engineering Education: The CDIO Approach, Bei Jing, pp:1-54, April 2009.

[2] E. Crawley etc. " Rethinking Engineering Education”. 2007,Springer.

[3] J. Zha, "On CDIO Model under 'Learning by Doing' Strategy," Research in Higher Education of Engineering, pp 1-2, May 2008.

[4] J. Zha, "Engineering Education Reform Strategy CDIO and industry cooperation and internationalization," China University Teaching, vol.5, pp.16-19, May 2008.

[5] Christopher Teoh, Au Siew Hong, Peh King Sing. "AN Integrated Approach To Teaching First Year diploma In Bioelectronics," Proceedings of the 3rd International CDIO Conference.MIT. Cambridge. Massachusetts.USA, pp 11-14, June 2007.

[6] Nhut Tan Ho. "A Framework for Improving Learning and Retention in a Diverse Student Population," Proceedings of the 2007 American Society for Engineering Education Pacific Southwest Annual Conference.2007.

[7] Q. Kang, X. Lu and G. Xiong, "CDIO syllabus and engineering innovative talents cultivate," Journal of Higher Education Research, vol.31, pp.15-18, Dec 2008.

[8] M. Li, "An Historical Interpretation of CDIO and its Application Prospects," Tsinghua Journal of Education, vol.29, pp.78-87, May 2008.

[9] N. Jiang, Z. Sun, "The Application for the CDIO Theory in the Reform of the Experiment Teaching of the Electric Engineering," Science \& Technology Information, vol.2, pp.643-644, Nov 2010.

[10] X. Shan, “The Experimental Teaching Mode Design of Linear Algebra Based on CDIO," Research And Exploration In Laboratory, vol.33, pp. 216-217, Dec 2014.

[11] D. Chen, "The Practice of the Introduction of CDIO into College English Teaching in Engineering University," Journal of Anhui University of Technology(Social Sciences), vol.27, pp.107-108, Feb 2010.

[12] J. Liu, “A Probe into the Multimodal College English Teaching Modal under the Principle of CDIO Idea," Journal of Chongqing University of Technology(Social Science), vol.26, pp.116-120, May 2012.

[13] F. Bi, B.Wang, "Research on Talents Training Models of Material Forming and Control Engineering under CDIO Guidance," Value Engineering, vol.32, pp.166-167, Feb 2010.

[14] J. Zha, "Engineering Education Reform Strategy CDIO and industry cooperation and internationalization," China University Teaching, vol.5, pp.19-20, May 2008. 